\title{
R1 - LATERAL FLOW IMMUNOCHROMATOGRAPHY AS A POTENTIAL TEST FOR YELLOW FEVER DIAGNOSTIC
}

Diana Praia Borges Freire $^{1}$, Alfredo Jabor ${ }^{1}$, Edimilson Domingos da Silva ${ }^{1}$, Jose Godinho da Silva Junior ${ }^{1}$, Ana Paula Dinis Ano Bom ${ }^{1}$

1. Bio-Manguinhos, Oswaldo Cruz Foundation, Technological Development, Rio de Janeiro, Brasil

Objectives: The present report describes the physicochemical characterization and posterior use of a yellow fever virus (YFV) antigenic protein for detection of antibody against YF. Yellow Fever (YF) is a viral infectious disease which can be transmitted to humans. The yellow fever virus (YFV) belongs to the Flavivirus genus and its genome encodes three structural proteins and seven non-structural proteins. The 17D vaccine protects against YF and is used worldwide in vaccination programs. Techniques for YF diagnosis are crucial for correct identification, prevention, control and reporting of this infection and lateral flow immunochromatography is a serological technique employed for the rapid, simple and economical detection of infectious diseases.

Methods: The protein was analyzed by isoelectric focusing ( $\mathrm{pH}$ range 3.0 - 9.0), SDSPAGE $12.5 \%$ and it was evaluated for detection of virus specific human immunoglobulin M (IgM) using MAC-ELISA. Lateral flow test components were evaluated in the immunochromatography model, such as different nitrocellulose membranes, variable antigen and immunogold conjugate concentrations and distinct running buffer formulations. Positive serum samples of individuals infected and vaccinated with the YF 17DD vaccine, unvaccinated negative and positive control antibody were used to evaluate a test prototype.

Results: Tests showed that recombinant YFV antigen did not cross-react with Dengue positive sera in MAC-ELISA. One prototype test showed $78.5 \%$ of sensitivity and $100 \%$ of specificity using serum samples of vaccinated individuals positive for immunoglobulin $\mathrm{G}(\mathrm{IgG})$. 
Conclusion: The data reported here are important for the further development of studies aiming at a rapid diagnostic test for yellow fever disease. 